\title{
Article
}

\section{Driving pro-environmental change in tourist destinations: encouraging sustainable travel in National Parks via partnership project creation and implementation}

Stanford, Davina and Guiver, Jo W

Available at http://clok.uclan.ac.uk/12755/

Stanford, Davina and Guiver, Jo W ORCID: 0000-0001-6126-3662 (2016) Driving pro-environmental change in tourist destinations: encouraging sustainable travel in National Parks via partnership project creation and implementation. Journal of Sustainable Tourism, 24 (3). pp. 484-505. ISSN 0966-9582

It is advisable to refer to the publisher's version if you intend to cite from the work. http://dx.doi.org/10.1080/09669582.2015.1122018

For more information about UCLan's research in this area go to

http://www.uclan.ac.uk/researchgroups/ and search for <name of research Group>.

For information about Research generally at UCLan please go to http://www.uclan.ac.uk/research/

All outputs in CLoK are protected by Intellectual Property Rights law, including Copyright law. Copyright, IPR and Moral Rights for the works on this site are retained by the individual authors and/or other copyright owners. Terms and conditions for use of this material are defined in the policies page. 


\title{
Driving pro-environmental change in tourist destinations: encouraging sustainable travel in National Parks via partnership project creation and implementation
}

\author{
Abstract \\ This paper explores a key challenge in introducing more sustainable transport practices at destinations: achieving modal shift in visitor \\ travel from cars to physically active or public transport to reduce tourism's environmental impacts. It centres on using partnership led projects \\ bringing together the many public and private sector organisations involved, to drive destination change and development. To date, research \\ has centred on pro-environmental change for individuals and individual organisations: little is known about the mechanisms of pro- \\ environmental change via complex multi-partner organisations. The paper reports research into the processes involved in successful projects \\ to provide alternatives to car travel in three UK National Parks by using partnerships to obtain funding and implement change. Based on case \\ studies informed by in-depth interviews with key stakeholders involved in pro-environmental change implementation, narratives are analysed \\ to explain the change process, and mapped against existing literature and theories of change. Conclusions show the role of inspired \\ individuals, supportive senior management, strong governance, better visitor experiences and, most significantly, communication, and \\ communication of the benefits of change to stakeholders. The research suggests why and how change occurs in partnerships, contributes to \\ better theories of change, and offers guidance on understanding and implementing change processes worldwide.
}

\section{Key words}

Sustainable visitor transport, change management, destination partnerships, pro-environmental behaviours, national parks, protected areas 


\section{Introduction}

Much has been written about the factors which lead to change towards more pro-environmental actions, both generally and within sustainable tourism. However, while there is an extensive literature about understanding individuals' (Barr, 2003; Jackson 2005; Torgler \& Garcia-Valinas 2005 ) and individual organisations' (Kane, 2009; Esty \& Winston 2006) potential to change, there have been few attempts to understand pro-environmental change in complex and dynamic partnerships such as tourism destination partnerships. These partnerships involve both multiple individuals and multiple organisations who need to be mobilised to achieve pro-environmental change within a destination area. Such partnerships are crucial because of the "... diffuse and fragmented nature of tourism development" (Bramwell \& Lane, 2000 p.1) even at a single destination, but need collaboration to achieve common goals. Partnerships differ considerably from companies and other organisations, notably because of different degrees of membership commitment, power, resources and skills within partnerships. Even more than companies, they function in an environment where they have little or no control over many factors which influence their success such as: the state of the economy, legislation, national and local political contexts, funding, technology and transport provision. In order to address the deficiency in the literature, this paper reports on the processes involved in two successful attempts to implement proenvironmental behaviour change (providing alternatives to car travel) by partnerships in National Parks in the UK and assesses the relevance of existing theories of managing change within companies to complex tourism partnerships. Although the case studies are British, similar tourism destination partnerships exist all over the world and the lessons from these case studies could have applications in many countries.

In 2011, the UK's Department of Transport announced the Local Sustainable Transport Fund (LSTF) allowing English local authorities to bid for grants to improve the sustainability of travel in their areas. English National Parks were allowed to make bids through their appropriate 
local Highway Authorities, and several submitted bids. Successful bids were received from the Lake District National Park Authority, and a joint bid from two National Parks, the New Forest and South Downs. All three Parks have a good record for innovation and encouraging car-free travel in their areas. Both projects have since been recognised as successful in reducing visitor car use (New Forest National Park 2014) and visitor-related greenhouse gas emissions (Tait, 2015), and have been awarded further grants from the LSTF (Department for Transport 2014). They demonstrate how partnerships can achieve pro-environmental changes, but also highlight the challenges involved, often because of the inertia or slowness of large and diffuse collaborations. They also illustrate the ways in National Parks, and other protected areas, can have a special role in implementing measures leading to more sustainable forms of tourism, because of their legal powers, fundamental aims and often because of the dedication of their staff members to conservation ideals.

This paper traces the processes involved in preparing and delivering the bids, through the reflections of people working in the local partnerships created to devise the bids and implement the associated projects. The paper describes the pathways adopted by the two partnerships and compares them with the literature and theoretical models of business change from key authors in this field (Doppelt, 2003; Kanter, Stein \& Jick, 1992; Kotter, 1996 and Luecke, 2003). The authors have drawn on the literature to describe the rise of public-private partnerships and some of the criticisms of the motives and processes involved. It draws on literature from business and tourism to explore the necessary and sufficient conditions for sustainable change to occur. The next section explains the context of the UK's LSTF and current changes in tourism destination planning. The methods section explains the data collection, analysis and presentation. The findings present the interviewees' explanation of their success in winning and delivering the bids, and the challenges they faced. The discussion draws together the key findings and relates these to the theories of change covered in the literature. In so doing, we build upon the work of Doppelt (2003);

Kanter, et al., (1992); Kotter (1996) and Luecke (2003) and have adapted these existing theories to suggest how pro-environmental change can be understood, not just for single organisations, but also for complicated partnerships. The adapted theoretical stages are transferable to other similar tourism contexts and provide guidance on how to implement pro-environmental changes which often elude destination planners. 
Overall, the paper advocates partnerships as pathways for policy learning, and the implementation of behaviour change tools and techniques, and suggests guidelines for partnership creation and management. It is important to note that this paper examines the operational and political processes involved in successful partnership based projects. It does not examine outcomes: a review of the outcomes of the projects discussed here can be found in New Forest National Park Authority (2014) and Cumbria Tourism (2015).

\section{Partnerships and change}

\section{Partnerships}

The need for collaborative working between organisations is growing as societies become more complex (Huxham \& MacDonald, 1992; Trist, 1983). Increasingly, governments are handing over duties previously undertaken by the public sector to private-public partnerships (Hall, 1999; Kjær, 2012; Reid, Smith, \& McCloskey, 2008) with hopes they will be less bureaucratic, more efficient and reduce the burden on the state budget and organisation (Williams \& Sullivan, 2007).

The move has been seen as ideological and criticised for reducing the systematic, rational view of the public interest (Ladeur, 2004), the loss of wider ideals such as equity, social justice and environmental conservation (Dredge \& Thomas, 2009; Selin, 1999) and as having a focus on economic benefits as the central measure of public interest. Local tourism provision and promotion inevitably requires co-operation between a variety of private and public organisations (Bramwell \& Lane, 2000) through some type of informal or formal partnership (Dredge, 2006), but the new context has brought new organisations to destination management (Stanford, Carter \& George, 2014) and granted more power to commercial interests and corporations (Hall, 2008; Pforr, 2001; Selin, 1999). This can lead to some partnerships prioritising their own economic interests over communal environmental benefit (Hall, 2014). 
The processes, as well as the aims, of the move to public-private partnerships have been criticised. McMurray (2007, p.77) suggests “...the political addiction to perpetual organizational reform" results in rapid changes in goals, organisation and personnel which destroy or prevent the formation of trust and often delicate channels of communication needed for collaborative working. Confusion over organisational identity can reduce staff morale (Glasby \& Lester 2004) and, in tourism, the move to public-private partnerships has resulted in a

“...fragmentation of agencies involved in tourism management” (Dredge \& Thomas 2009, p. 249).

Partnerships, formed voluntarily when organisations cannot achieve their goals independently (Huxham \& Vangen, 2005), encounter a number of intra-member problems such as differences in aims, language and culture, power imbalances and the time needed to reach decisions (Huxham, 1993) which may result in 'collaborative inertia' (Huxham \& Vangen, 2009, p. 30) if not swiftly addressed. The partnership formation may be precipitated by a crisis or changes in the economic, competitive or technological environment (Wang \& Xiang, 2007) creating a collective desire for change that cannot be achieved independently. Inevitably motivations and objectives between partners differ (Bramwell \& Rawding, 1994), but most potential partners will, and do, ask "what is in it for me?" (Purvis, Zagenczyk, \& McCray, 2015, p. 3). Communication is seen as key for establishing and maintaining a partnership (Williams \& Sullivan, 2007) although language may have to be tailored to different audiences to reflect their experiences and perspectives (Huxham \& Vangen, 2005).

Although common goals are important (Nooteboom, 2002), synergies can be created through differences in partners' purposes, resources and expertise which allow partnerships to achieve higher objectives than attainable working independently (Huxham, 1993). However, even where irreconcilable differences prevent agreement, some collaborations pragmatically “...get started on some action" leaving joint discussion until something has been achieved (Huxham \& Vangen, 2005, p.3). Individuals within partner organisations may have their own "personal, professional or work-related reasons" for promoting partnership working (Williams \& Sullivan, 2007, p.18). 


\section{People, organisations and change}

There is a growing recognition of the importance of key people in the successful delivery of change and of projects (Hornstein, 2015; Nauman, Khan, \& Ehsan, 2010). As Cooke-Davis (2002, p. 5) observes, “...it is people who deliver projects, not processes or systems", while Leybourne (2006, p. 61) observes a "...changing bias from tools and techniques, toward the social and behavioral aspects of the management of projects". These individuals are often working in "shifting landscapes" and when careers may cross sectors, employees "seek to orient themselves" as they develop in a "precarious" and "pluralist" environment (Tams \& Marshall, 2011 p. 109). Some employees aim "to have an impact on societal challenges such as environmental sustainability and social justice through their employment and role choices, strategic approaches to work, and other actions" (p. 110) rather than directly choosing personal advancement. In terms of Hofstede's (2015) understanding for organizational culture this may be viewed in terms of goal-orientation, whereby employees are motivated to achieve “...specific internal goals or results, even if these involve substantial risks".

Tourism partnerships bring together such people from public and private sectors, which can result in a clash of cultures (Wray, 2011). Russell and Faulkner (1999) argue that the different mentality, goals and worldviews of those working in the private and public sectors will always create tensions. They characterise the public sector employees as moderators of change, being risk averse, wanting continuity, stability and consensus, who may also be less responsive to local circumstances because of rigid bureaucracy. In contrast entrepreneurs are seen as "chaos-makers", generators of change (Lewis \& Green, 1998) flexible and open to new opportunities (Russell \& Faulkner, 1999), a view echoed by UNWTO (2007) which depicts the public sector as slow, but strategic and the private sector as quick in decision-making, but lacking concern for the wider good. Unlike private companies, partnerships do not have an over-riding executive officer, so change requires consensus, 
engagement and commitment from the partners. Yet, visionary leadership or champions with “...drive, energy and enthusiasm” (Speakman \& Transport for Leisure Ltd, 2008, p. 8) are often critical for starting (Gray, 1989; Selin \& Chavez, 1995; Wang \& Xiang, 2007) and maintaining tourism partnerships and acting as brokers between parties.

Change within organisations is challenging. People often resist change unless they see its benefits (Doppelt, 2003; Kane, 2009), and organisations, composed of individuals and groups, have “...constantly changing interests, needs and allegiances" (Doppelt, 2003, p. 79). Todnem (2005) identifies a number of common conditions necessary for change among the findings of leading authors (Kanter et al.; 1992 Kotter, 1996; and Luecke, 2003): creating a vision, establishing a sense of urgency, creating strong leadership, creating a strong coalition, enabling the employee, communication and institutionalising the change in culture. These are shown in Table 1 alongside Doppelt's (2003) seven 'leverage points' necessary to improve sustainability in organisations including: transformation of norms and values; changes in governance; and providing employees and stakeholders with credible information, "Meaningfully involving them in decision-making will generate ownership and personal responsibility" (p.80). He concludes that a coherent theory of success from leadership is required to change processes to incorporate "...the people, units and processes within their organisations, as well as its many stakeholders" (p. 82).

Table 1: A comparison of four stages of change

\begin{tabular}{|c|c|c|c|}
\hline $\begin{array}{l}\text { Kanter et al. } 10 \text { commandments for } \\
\text { executing change (1992) }\end{array}$ & $\begin{array}{l}\text { Kotter's eight-stage process for } \\
\text { successful organisational } \\
\text { transformation (1996) }\end{array}$ & Luecke's seven steps (2003) & Doppelt's Leverage points (2003) \\
\hline & & & $\begin{array}{l}\text { Change the dominant mind-set and } \\
\text { point out failures of the old paradigm, } \\
\text { describe why new one is better }\end{array}$ \\
\hline $\begin{array}{l}\text { Analyse the organisation and its need to } \\
\text { change }\end{array}$ & & $\begin{array}{l}\text { Mobilise energy and commitment through joint } \\
\text { identification of business problems and their }\end{array}$ & $\begin{array}{l}\text { Alter goals of the system and establish } \\
\text { the unambiguous purpose of attaining }\end{array}$ \\
\hline
\end{tabular}




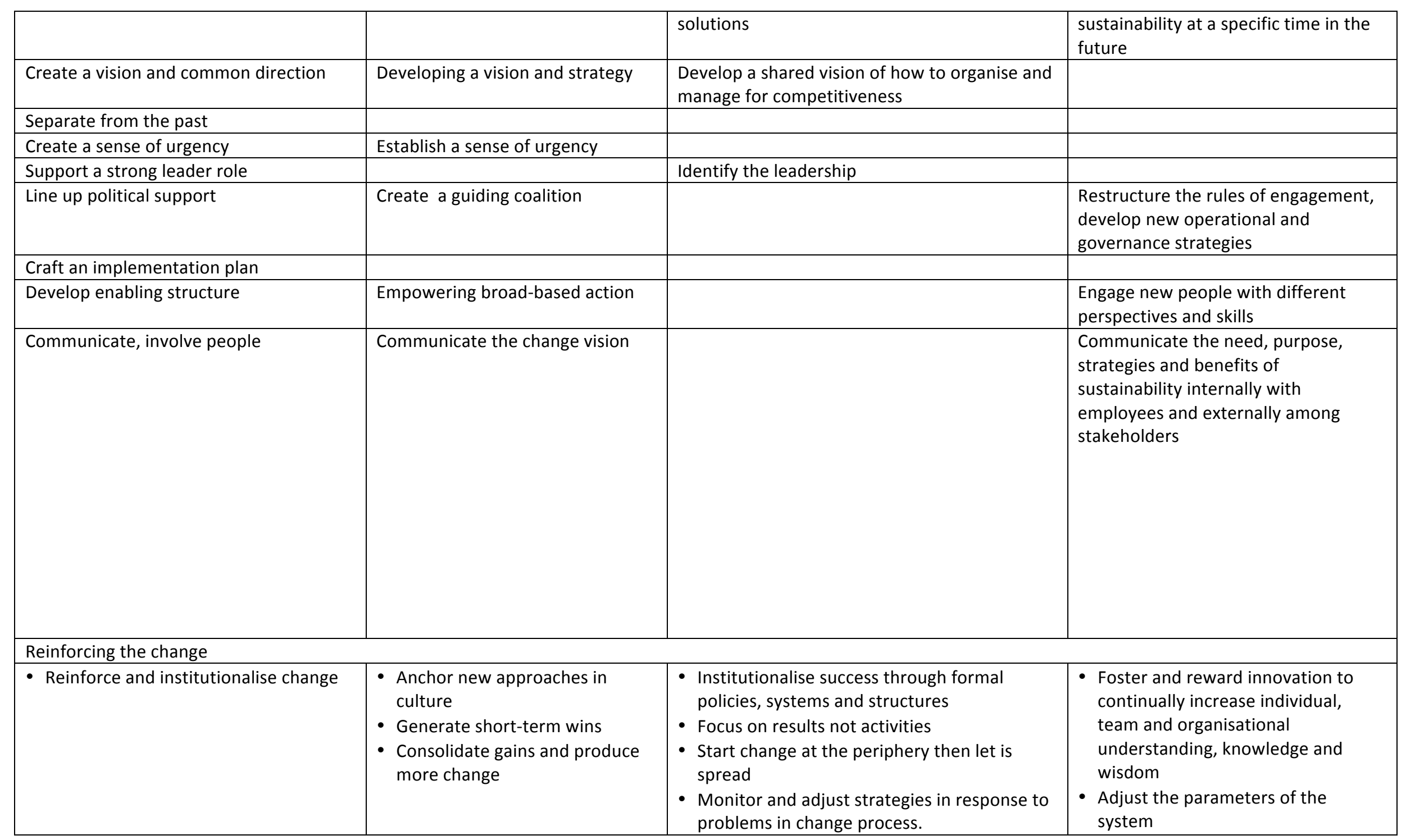

Adapted from Todnem (2005) and Doppelt (2003) 
Amid pessimism about the motives for and processes associated with the political move to more partnerships, the literature from business, public administration, partnership working and tourism hints that there are may be several necessary and sufficient factors and processes for partnerships to implement pro-environmental change. These include: key people, communication skills and identifying benefits to stakeholders. In addition, authors writing about change in organisations, have identified critical stages which are tested in this research.

\section{Context}

The management of tourism and tourist destinations has undergone considerable change in England during the last decade (Stanford et. al., 2014). Perhaps the biggest impact has been the ending of nine Regional Development Agencies (RDAs) and their replacement with 39 Local Enterprise Partnerships in 2012. Each RDA, the majority of their staff drawn from the public sector, was responsible for a region of England and promoted economic growth, efficiency, employment and sustainable development, using central government money. Local tourism projects and promotion were supported in areas where tourism offered potential for local employment and development, including areas away from traditional tourism hotspots. The Local Enterprise Partnerships (LEPs) (House of Commons, 2013), charged with promoting local economic development, must be chaired by a business-person and at least half their members must be from the private sector (Ward, 2015). Their funds come from bids to the central government's Regional Growth Fund, the Single Local Growth Fund and the Growing Places Fund with matched funding from local partners from both private and public sectors. They also administer EU Structural and Investment

Funds. They steer much of the strategic vision for their areas. Tourist destinations in the UK rarely have a single organisation responsible for destination management, even in National Parks, and rely on networks of local organisations to contribute to policy-making and tourist provision in their areas. 
The Local Sustainable Transport Fund was introduced in England in 2011, following publication of a White Paper: Creating Growth, Cutting Carbon (Department for Transport, 2011) which describes the benefits to employment and carbon reduction of replacing car journeys with physically active or public transport modes. It also stressed how local knowledge and decision-making would make sustainable travel provision more effective. The Department for Transport (DfT) originally allocated $£ 560$ million to the scheme, expecting authorities to contribute to each award-winning project. A further $£ 40$ million was added by the DfT in 2012 resulting in a total of $£ 1$ billion (including additional contributions from local government and other organisations) being invested in sustainable transport in 96 projects (Transport for Quality of Life, 2015). The main criteria for assessing applications were: local economic development and reducing carbon emissions. Safety, improving air quality, reducing noise, promoting physical activity and "wider social and economic benefits" were also considered (Department for Transport, 2011). It is noteworthy that the majority of projects were not about sustainable transport for tourism, but for other activities. Applications for funding had to be made by a local government transport authority, although projects could cross authority borders. National Parks were included in the funding scheme following lobbying by National Park officers but their bids needed to be submitted by a local highways authority.

The Lake District National Park Authority and Cumbria County Council applied for $£ 4.89 \mathrm{~m}$ funding in April 2011 and were notified of their success in June 2011. The total calculated cost of $£ 6.9 \mathrm{~m}$ for the "Go Lakes" project included contributions from the Lake District National Park Authority, Cumbria County Council, local bus and boat operators, Cumbria Tourism and several local businesses. The bid consisted of nine 'packages' designed to enhance public transport, reduce emissions, introduce a smart public transport ticket for the area, promote cycling, including electric bikes, improve information, marketing and confidence in using public transport and persuade visitors of the benefits of arriving in the Park by public transport. The bid only related to the South Lakes portion of the National Park, which has the highest proportion of visitors. 
Hampshire County Council, the New Forest and South Downs National Park Authorities together applied for funding of $£ 3.81 \mathrm{~m}$ for projects costed at $£ 18,283 \mathrm{~m}$, which was approved in June 2012 , the remainder coming from the six transport authorities in the National Park areas, both National Park Authorities, transport providers, including Network Rail and tourism providers. Advisors involved in the Lake District bid assisted the authorities in writing their bid, which promised improvements to public transport gateways to the parks, information and marketing for visitors before and during their visit.

\section{Methodology and method}

This study explores the processes and relationships involved in successful visitor travel planning partnerships, to understand the how and the why behind partnerships seeking a change towards more pro-environmental behaviour. Because this is an under-researched topic, it required an exploratory approach. Thus, it was decided to adopt an in-depth case study methodology which allows the researcher to "...retain the holistic and meaningful characteristics of real-life events" and understand the relationship between the object of study and its context (Cavana, Delahaye \& Sekaran, 2001). This also lends itself to the generation of theory (Finn, Elliot-Whyte \& Walton, 2000) which can then be tested in other contexts and has been successfully employed in similar transport research (see, for example Pearce, 2014).

Three study areas in receipt of two LSTF grants were selected for investigation: the Lake District, the New Forest and the South Downs. The Lake District was an independent bid, with the other two areas collaborating for a joint bid (covering two separate geographic areas). All three areas were chosen on the basis of being successful in winning LSTF funding and also receiving another Department for Transport grant to explore the added-value of visitor-focussed travel schemes, increasing their comparability. These areas are also recognised destinations, characterised by well-defined administrative areas (March \& Wilkinson, 2009; UNWTO, 2007) and grounded conceptually in geographic place 
(Pearce, 2014). Both bids and subsequent projects were set up and operated through partnerships assembled initially for the purpose of compiling the bids. Participants in the bid partnerships represented existing stakeholders in the destination. The work of delivering the projects was largely the responsibility of the individual National Parks, while the local council was the accountable body. Project staff were employed for the delivery of the project: many had ties with the area or had previously been employed by project partners.

Qualitative research was more appropriate than quantitative, as it can explore complex situations, with multiple viewpoints and can generate data which reflects the views of the participants rather than those of the researcher (Bryman, 1995). Semi-structured interviews were conducted with key stakeholders who were involved in the development and delivery of the projects. These allowed the participants flexibility pursue topics which were of importance to them (Bryman, 1995). The semi-structured nature of the interviews allowed both for comparability, but also for interviews to deviate at points of particular relevance and interest to the participants. The interview schedule included questions relating to the success and failure of the initial bid, the partnership and the process of the delivery based on Pawson and Tilley's (1997) Realist Evaluation. Realist evaluation seeks to evaluate the nature of social programmes and asks questions not regarding what worked for the programmes being evaluated, but rather asked what were the circumstances and mechanism of success. In practice, this process involved framing questions around resources, people, institutional and political factors, procedures and outcomes.

The initial interviewees were chosen on the basis of a purposive sample of partners in the original funding application. They were asked to identify other useful interviewees according to snowball selection. In total 17 participants were interviewed, including a mix of representatives from the public (10), private (5) and voluntary sectors (2) (See Table 2). Participants were first contacted by telephone or email to arrange a suitable time for a telephone or face-to-face interview. The interviews, lasting between 45 minutes and 2 hours, were audiorecorded, with interviewee consent, and notes were taken at the time. The audio-recordings were transcribed and interviewees assigned a number to protect their anonymity.

Table 2: Summary of research participants 


\begin{tabular}{|l|l|l|}
\hline $\begin{array}{l}\text { Allocated } \\
\text { No. }\end{array}$ & Sector in which working & Case study area \\
\hline 1 & Private Sector, Tourism Organisation & Lake District \\
\hline 2 & Private Sector, Tourism Organisation & Lake District \\
\hline 3 & Public Sector, National Park & Lake District \\
\hline 4 & Public Sector, National Park & Lake District \\
\hline 5 & Public Sector, Local Authority & Lake District \\
\hline 6 & Private Sector, Transport Provider & Lake District \\
\hline 7 & $\begin{array}{l}\text { Private Sector, Attractions Owner / } \\
\text { Manager, Transport and } \\
\text { Accommodation Provider }\end{array}$ & Lake District \\
\hline 8 & $\begin{array}{l}\text { Private Sector, Attractions Owner / } \\
\text { Manager and Transport Provider }\end{array}$ & Lake District \\
\hline 9 & Public Sector, National Park & South Downs / New Forest \\
\hline 10 & Public Sector, National Park & South Downs / New Forest \\
\hline 11 & Public Sector, Local Authority & South Downs / New Forest \\
\hline 12 & Public Sector, Local Authority & South Downs / New Forest \\
\hline 13 & Public Sector, Local Authority & South Downs / New Forest \\
\hline 14 & Public Sector, Local Authority & South Downs / New Forest \\
\hline 15 & $\begin{array}{l}\text { NGO / voluntary sector, Community Rail } \\
\text { Partnership }\end{array}$ & South Downs / New Forest \\
\hline 16 & $\begin{array}{l}\text { NGO / voluntary sector, Community Rail } \\
\text { Partnership }\end{array}$ & South Downs / New Forest \\
\hline 17 & Public sector, National Park & South Downs / New Forest \\
\hline
\end{tabular}


A thematic method of coding (Ryan \& Bernard, 2003, p. 88) was adopted allowing “...themes to come both from the data (an inductive approach) and from the investigator's prior theoretical understanding of the phenomenon under study (an a priori approach)". An iterative approach was used in the analysis of the data. The initial stage of the process was to make notes during the transcription process and to highlight quotes which seemed important. This process of identifying 'key quotes' was repeated once the transcripts were printed, with these quotes organised according to a card sort, as outlined by Ryan \& Bernard (2003) where quotes which have been identified as significant are sorted into piles of similar quotes, from which the themes emerge.

Despite the relatively small sample size the data are considered sufficiently robust because the point of saturation was reached, whereby new interviews were not contributing new insights (Bowen, 2008). Some potential participants were unavailable because of time pressures or had already left their role. Qualitative research relies on participants' subjective views, and in this case, were based on their recall, but generates rich narratives. The findings report themes corroborated in different respondents' accounts.

\section{Findings}

\section{Summary of themes}

The findings are split into four sections following the timeline of the LSTF funding application and project delivery. This sequential narrative both reflects the stages of the process and the way in which research participants recalled that process. It also illustrates the importance of the time-links of the data (as one stage could not occur without the preceding stage). Within these chronological points, key 
themes have emerged, recognising that the documented phenomena were “...bigger than specific "events"." (Miles \& Huberman, 1994, p. 119).

The first section focuses on understanding the pre-existing conditions within which the initial funding proposal for the LSTF funding was developed. It reports on contextual factors facilitating change and also those posing challenges to the intended change / project, including the political environment and the organisational cultures. The key theme emerging from this section is the significance of both facilitating and hindering governance and government conditions. The theme emerging from the section about bid preparation relates to the different approaches taken by the different bid applicants, characterised by risk in one case and rigour in another. The third section discusses considerations during the process of change (i.e. the delivery of the project itself). Key themes include time constraints; governance and partnerships; communication and communicating the benefits to all stakeholders; selling the visitor experience and 'speaking the right language'. The final section looks to the future and explores the approaches required to anchor the changes implemented in visitor travel as a result of the LSTF funded project, this includes respondents' critiques of short-termism and the importance of financial viability. This section is characterised by the ongoing tensions and intentions of the public and private sector.

\section{Pre-existing conditions prior to obtaining funds to implement change}

\section{Governance and government}

Even before the bid was prepared, some pre-existing conditions, particularly with regards to the political context, appear to have been conducive to make visitor travel more sustainable. These enabling (and disabling) conditions were apparent at national, regional and local 
level. For example, one interviewee related how changes in government policy about funding transport projects created a suitable climate for the LSTF.

There has been a shift in government policy thinking.... One, towards revenue based sustainable transport and funding sustainable transport generally and two, through Government shifting from strategic policy from which funding followed to chucking money at deliverable projects, which then led to the fund, which led to the National Park getting money for visitor travel. [3]

Although government policy is normally regarded as an exogenous factor in destination planning, one of the participants believed that his persistent lobbying was probably instrumental in including National Parks in the call for bids.

Other pre-existing states and processes, however, were less favourable to encouraging provision of non-car visitor travel facilities. These included the trend away from assessing projects on broad public interest criteria, to only considering economic development, with the replacement of the RDAs by Local Enterprise Partnerships (LEPs).

(LEP and Local Growth Fund) it is all driven by economic growth... You get prosperity through a better quality of life, not solely from economic growth... The political agenda has shifted to economic growth and transport is not seen to help the economy. So it's difficult to justify transport stuff for other reasons like health or the environment, unless you can show it is good for the economy. To make the economy healthier you have to do the other things too-maximise the quality of the experience, and you can do this in part from transport. But you can't measure that. Carbon is only of interest if it is monetised. The economic benefits of cycling such as the health savings. We shouldn't have to monetise this. We should just be able to proudly to say there are health benefits. It warps and skews priorities. The LEP structure is insidious. [3] 
More long-standing attitudes amongst local authorities were also seen as obstructive to encouraging more sustainable visitor travel. This was because for many local politicians sustainable visitor travel was not regarded as important as transport services for residents, and voters, despite the potential of much greater carbon savings from more sustainable visitor travel.

The County Council pay lip service to visitor transport, they are much more interested in moving residents and the business community around and frankly they are not that bothered about the visitor because they don't vote. They have no statutory requirement and they tend to back off. If you look at their objectives outside of the LSTF bid, it's about ease of access to work or schools or doctors and shops. But if they really want to make some bite sized chunks into carbon reduction, congestion, air quality, then they should be going for the visitor. [2]

The parochialism of local politics could also threaten innovation, with local councillors being pressurised to support their own area and constituents, rather than the common good.

... the political environment wasn't easy. The National Parks has a board which is made up of locally elected members and nationally appointed members... all are meant to operate in the interest of the National Park as a whole but obviously this doesn't happen in reality and some want to fight for funding to be spent in their particular area. I remember examples of $x$ being called up directly by members asking what was happening in their constituency... [17]

At a local level, in the opinion of some participants it was preferable for the local authority involved to be avoided altogether. If the bid had value distinction and quality, it's because it was unencumbered by local politics. [3] 


\section{Preparing the Bid}

\section{Risk and Rigour}

Two very different styles emerged when participants talked about bid preparation. In the Lake District, one officer was given licence by a senior manager to 'just get on with it' and to circumvent many of the required bureaucratic processes which should have been followed with key potential partners such as the County Council. This risky approach was adopted because of a perception that such involvement would slow down the process overly or possibly stall it altogether.

But if we had done everything as we should, we would never have got the bid submitted, let alone been successful. Sometimes, you just have to get on with it. f5M, it's the biggest single amount of money to go the Lakes. The scale of it was worth taking the risks. [3]

This approach was, in part, due the culture of the National Park authority which encouraged a 'can do' attitude. The Park Authority have a culture of just go and get on with it, if it's a good idea.... I would argue that giving money to non-transport organisations to do transport solutions is a highly cost effective way of getting stuff done because transport authorities are large, cumbersome authorities that take a thousand years to decide to do anything. Whereas we just think, let's get on with it... We're solutions 
focussed.... People recognised that in order for it to work it couldn't be designed by committee. The CEO was brave to allow me to do this. [3]

While this approach enabled the bid to be completed and submitted swiftly, it created difficulties later when the necessary systems and structure were not in place to deliver the projects, after the award.

The bid was easy to put together, but stuff came back to haunt us, all the stuff with the County Council getting stuff signed off. But we didn't have time and if we had asked them they would have just have said no, so it would never have happened. The first year was a ... disaster because we didn't have all the i's dotted and the t's crossed. [3]

Such an approach would have been more difficult for the New Forest and South Downs as three public organizations two National Parks and Hampshire County Council were involved from the outset. The officers writing their bid established a strong and rigorous governance structure before submission which took time and negotiation to include some 90 or so partners. This was in place for the award and the successful delivery of the funded projects was, in part, attributed to this.

Some went to formal committees. Others didn't show it to members. Whatever each authority felt comfortable with. But it had to get letters of support and that was difficult. ... 90 organisations giving support, which were named-we got these to put the letters in. The main thing was that everything in the guidance was addressed in the bid. And to make it sound exciting and innovative and inspiring. That can be difficult in local government, but that was something that I wanted to achieve.... The Terms of Reference were quite specific in what each board could or could not do so everyone was clear on what their remit was and where they were empowered to make decisions and where they weren't and they were well chaired and everyone knew what had to happen by what time. [10] 
The very different approaches possibly resulted from the tight deadline for the Lake District, who prepared their bid in a few months for the Tranche 1 funding in 2011, while the New Forest/South Downs bid for Tranche 2 funding in 2012 and learnt from the experience in the Lake District, employing two consultants who had worked on the Lake District bid. The deadlines, both for submission of the bid, but also for each year's budget and the end of the project certainly produced a sense of urgency, galvanising project partners. Time scales may appear to be only of minor importance, however, in practice, they can be major determinants.

\section{Considerations during the process of change: the delivery stage}

\section{Time Constraints}

Many of the interviewees spoke of the rush to achieve the goals within delivery period. Rushing the process could lead to the wrong priorities being identified and would, therefore, ultimately be unsustainable. The money was awarded for a three year period, so some staff could not be put in place immediately to take advantage of the funding and, in any case, three years was not seen as long enough to tackle and change a firmly entrenched behaviour (visitor car dependence) or for some business ventures to become commercially viable. Finally, there were concerns that expertise was lost as staff started to look for alternative employment before the three years ended.

Funding should not be time-limited. It takes longer than three years and then it ends up being not about what needs to be done, but about what money is available and what can be done in that time. [15] 
This rush contrasted with the time needed for partnership working, doubly frustrating when they knew funds could not be carried over from one year to the next, if there were delays. This was illustrated by one example from the Lake District where it took almost 18 months to get approval for bus stop flags along a cycle route. Permission requested from the Highways Authority in the spring of 2013 involved a site visit. However, this could not be arranged until September 2013, followed by a requisite consultation process resulting, some months later, in approval. Subsequent delays and staff changes meant the allocated funding for that year was lost and the application returned to the starting point.

\section{Governance and partnership}

The delivery stage success, for the New Forest / South Downs, was attributed in no small part to the governance structure, and in particular the opportunity that this afforded for partners to report back, to discuss their differences and to find a compromise or solution where disagreements occurred.

It was very much a partnership approach ... The approach worked quite well, there were various meetings, lots of email, and phone calls, delegated responsibility, tasks divvied up. ..It had to be signed off by all highways authorities and local authorities. [10]

The same respondent continued that there were additional benefits to the broad partnership:

But this was an added benefit that it brought highways authorities and National Parks together. That worked really well. Ideas bounced off each other. The learning from that went beyond LSTF. [10]

In the Lake District, however, the lack of a suitable framework led to difficulty in implementing the project. 
They had a difficult time with that [the delivery] because they hadn't really sorted out the governance before they submitted the bid. Cumbria County Council was the accountable body and once they got the money they talked about how it was going to be delivered and they hadn't really bottomed that out before. [5]

Even though the New Forest / South Downs attributed success to their strong governance, the partnership was not without challenges; the breadth of the partnership and the complexity of the management structure was difficult at times. Participants mentioned challenges including negotiating political and administrative boundaries with multiple local authorities; the numbers of partners involved and the difficulties of coordinating them (there were 90 partner organisation involved in the New Forest / South Downs. This resulted in uneven levels of commitments from the partners; conflicting priorities; a dilution of the vision and a subsequent need to compromise.

Within the governance structure, there were clearly recognised roles for different partners. The private sector, for example, saw their role as enabling and side-stepping the laborious bureaucracy of the public sector:

One of the beauties of our involvement is that we are largely free of bureaucracy that the County Council and the National Parks have and that allows us to respond quickly. [2]

while the public sector saw their role as facilitating and enabling others by creating orderly frameworks:

The real world is quite messy and complicated and what we like to do is create frameworks for working so that it makes the real world a bit less complicated, so that other people have a clearer understanding of what our shared priorities or aligned priorities are. [3] 
A recurring theme related to communicating the benefits of the project as a way of getting partners involved and keeping them motivated. Indeed, success in the Lake District was attributed in no small part by the following participant, to the effective communication of Cumbria Tourism and the Go Lakes project:

The single most important factor of success? The communication. The projects are great, but if they happen alone, then it's not good enough. Because if people aren't aware then they will fail. I think Cumbria Tourism have done some really good communications work as have the Go Lakes partnership. And really got the communication out. [7]

The issue of communication was most pertinent for stakeholders unconvinced about the value of the project who were, initially, reluctant to give the funding application and the subsequent projects their support. This was particularly so for local residents and the councils representing them. Participants in the Lake District reported that the initial reaction from the local council was one of reluctance. Councillors were not overly supportive of initiatives which promoted (non-voting) visitor transport. Residents also opposed the LSTF project which they saw only as benefiting visitors and not the people living there. Questions were asked why money would be invested in providing services for visitors and not, for example, for repairing potholes in local roads.

It was essential, therefore, that residents understood the aims and benefits of the project both before inception and during the delivery and that they were aware that the services would benefit them both through amenities they could use themselves and in the reduction of localised car-related pollution and congestion.

...if anything does look like it is presenting a change it has to be carefully communicated. We stated that this would enable people to make a choice and that it would make sustainable transport easier and that residents could use that too. So we had to communicate carefully. [10] 
In the New Forest, the following participant outlines the challenges which were faced because of the focus on visitors and the need to convince local communities of the benefits:

For the New Forest, the biggest barrier was convincing local communities... that this investment would benefit everybody. Because in order to get the money we had to make the focus ... on visitors which made residents feel uneasy because there is a tension between residents and visitors. We had to demonstrate that the benefits were for everybody and not just visitors. But for DfT (the Department for Transport) the focus clearly had to be visitors. So there was some careful communication which needed handling... We stated that this would enable people to make a choice and that it would make sustainable transport easier and that residents could use that too. [10]

Local residents in the Lake District were also opposed to some of the plans which were delivered as part of the project and communication was seen as crucial to managing relationship with residents. This participant acknowledged residents should have been engaged, and the benefits explained, much sooner in the project.

Some community groups have complained ... but when we speak to them they realise there is a benefit. It's more a perception than a reality....Communicating with the local community was not built into the project, and that perhaps was a weakness particularly at the beginning as there wasn't any lead time. The announcement came, the money was available, and ... that turned very quickly into the need to deliver and spend the money. I think we missed an opportunity to engage local residents after the bid announcement had been made. [5] 
One bus operator in the Lakes articulated his thoughts on the benefits from a business perspective and also on the issue of communicating the benefits succinctly. This participant clearly saw the benefits of sustainable visitor transport planning to a range of stakeholders including visitors, the economy the local council and the operators themselves:

From both a business view and from a sustainable view we need to get cars off the road. Cars off the road helps us, it helps the tourists, it helps the economy. And a person who likes to visit here will like that feel of less traffic... I think it is on the agenda now and has moved up people's priorities... Pollution is a big priority for the councils and there is a commitment to reduce that. So something's got to be done you can't just keep letting the numbers increase...I'm keen to work with anyone, I'm passionate about it. Let's get everyone on a bus and ensure that everyone benefits. [6]

Other participants pointed to the logic of targeting visitors rather than residents because of the potential scale of carbon saving. ...there is a resident population of 500,000 and 16 million visitors a year, so if you really want to achieve some significant carbon reduction in terms of travel behaviour you need to work on visitors... We always went into it that it would be easier to influence visitor travel behaviour than residents. They have more time and are more amenable. Open to new experiences perhaps.... [1]

Local Economic Partnerships were also considered to be motivated by growth and, therefore, the messages for them needed to refer to economic opportunities rather than sustainability:

The LEPS are all about economic growth. Our focus is on sustainable tourism and we need to attract new types of visitor - ones who (can) have economic contribution but not arriving by car and the offer has to appeal to them. If you can make the economic case then the LEPs are supportive. Sustainable travel is not high on the agenda; they want to build roads as they see this as crucial to the economic growth of the area. [13] 
Clearly communicating the benefits was crucial to the success of the projects. Many of these participants felt that focussing on the visitor experience was also critical. Several research participants noted that the private sector were not motivated by visitor transport provision per se, but if the provision of transport enhanced the visitor experience then this would be of much greater interest to them:

The private sector see transport as a secondary thing. They see the visitor experience as the most important thing. It's difficult to engage them by saying how important sustainable visitor transport is, but they are interested in the visitor experience. [2]

A participant from the private sector concurred with this sentiment, highlighting the important of creating a quality experience for the visitor:

Personally and professionally we're interested in understanding how we can get visitors to spend less time in their cars. We're passionate about this. This can help people learn more about the area, not just drive past it. You can really get a feel from this from public transport, you can experience more... The company brand is not cheap; it offers good value for money. But the staff quality, customer handling, the friendly staff enhance the whole experience. That's what we're about as a company. [8]

One participant gave a particularly powerful example of a successful bus service and an explanation behind this success. First and foremost success was attributed to an innovative and creative approach to no longer view the 'service' as merely a bus journey, but instead to view it as a visitor attraction, offering a rich visitor experience (free ice-creams included). In the following quote it is important to note the fact that the service also helps support communities and is on track to become commercially sustainable: 
We took a failing rural service which only ran 3 days a week in sparsely populated rural areas in the summer months, we rebranded it and reinvented it, tweaked the route to take in more attractions, offered a free ice-cream, and gave it a retro feel. It's on track to be commercially viable for the summer at least and it connects all the communities and services on that route. We don't see it as a bus, we see it as a visitor experience...if you think of it as a bus it requires a subsidy, if you think of it as a visitor attraction, it will make a profit. [9]

\section{Speaking the right language}

Many participants discussed the importance of choosing the right language both to encourage visitor behaviour change and selling the value and benefits to potential partners. Sending the right message, presented in the right way, was considered crucial to engaging many of the stakeholders. For the private sector, for example, the message needed to emphasise the potential for growth:

Engaging with the private sector is always interesting. There has to be a measure of getting to them to understand the possibilities and why they should get involved making it worth their while... Why has the private sector been engaged? It's a very practical project. It speaks their language. It's about growing their numbers.... [7]

How do we re-pitch and rephrase travel planning so we can get businesses to engage? We need to be outcome focussed - what is their corporate and business incentive to achieve our outcomes? We need to show them the benefits. It's down to the language you use, the semantics, you need a linguistic. The New Forest tour doesn't mention it is a bus. It's about visitor experience, not about transport. The good stuff is about the visitor experiences, that's what we want, we want visitors to have a good time and come back; it's not about telling them to get on a bus. It just isn't. [3] 
There was also a recognition that the public sector had to meet the private sector on their own terms and frame the propositions to the private sector in a way that they understood and which appealed to them:

We [the public sector] need to be a bit less lazy and talk more business speak, frame whole propositions, questions and problems in the language, context and ethos of the private sector because if the private sector don't want to pick it up we just end up pouring public money down a hole. [3]

\section{The Future and anchoring change}

\section{Public and private partnerships: tensions and intentions}

Many of the interviewees regretted the short time span of the projects and were worried that sustainable visitor travel would not be sustained very long after the end of the funding. They stressed the importance of involving the private sector in continuing the initiatives, but were concerned that economic, rather than wider aims would predominate.

...we're dependent on them [private sector] for the long-term legacy. If they see it as having possible potential for their business for the future then they are far more cooperative. [4]

The growing influence of the private sector is a problem, because of their focus on making a profit... I fear that the focus on economy, economy, economy will be at the expense of the environment. [13] 
Some believed the public sector would still need to be involved, partly because sustainable visitor travel was unlikely to ever be commercial.

The private sector and businesses making the most of opportunities. We [the public sector] say to them we have put infrastructure in, now that is up to you. We've tried to put things in place that they can carry on using. Their role is to use these and sell the experience to the visitor. [5]

Visitor transport is not commercial because it is of a wider remit than a company or business can provide and I don't think it will ever be commercial. [15]

There were worries that the LEP would not appreciate the value of sustainable visitor travel, because of their focus on economic value and sustainable visitor travel was seen as vulnerable to being supplanted by other priorities.

Spending and decision making power has evolved to the LEPS. ... But sustainable visitor transport is not very important to them, urban and rural resident transport is more important, sustainable visitor's transport is not a priority for anybody. [14]

In the situation if something is squeezed [financially] this will fall by the wayside. ... In order to make it a priority all the current partners have to see the value in what we're doing and that may see some results. [15]

\section{Discussion}


It is clear that many of the elements considered important for implementing and sustaining change in organisations are also relevant for these tourism destinations in their efforts to embed pro-environmental change by encouraging visitors to adopt non-car travel (See Table 3 for a summary).

Some of the pre-existing conditions were helpful to bringing about change such as the establishment of the Local Sustainable Transport Fund, the inclusion of National Parks in the call for bids and the Government's focus on revenue support. However, the move towards more private sector involvement though the LEPs and the focus on economic returns rather than other forms of public good such as equity, health and environment (see Dredge \& Thomas, 2009; Selin, 1999) was perceived by participants as hindering the long-term survival of the projects after the funding.

Several of the participants seem to have seen themselves as working against this culture to deliver environmental, health and area benefits and there is evidence that they had chosen these roles because of their commitment to goals other than self-advancement. In this way, they appear to resemble the people identified in Tams and Marshall's research (2011) into responsible careers, who chose jobs to satisfy their desire "to have an impact on societal challenges". The temporary nature of most of the posts certainly placed them in the "shifting landscapes" of cross-sectoral employment, although the temporary nature of the work failed to anchor their expertise.

As suggested by Speakman \& Transport for Leisure Ltd, (2008) and Wang and Xiang (2007), inspirational leadership was important for the successful bids and project delivering in partnerships. In contrast to companies, where a CEO is granted leadership powers, leadership in partnerships emerges from action. Several participants believed that the personal persuasions of individuals and their power to influence would be crucial for the continuance of the schemes. This aligns closely with the literature: the importance of people (Cooke-Davis, 2002; Hornstein, 2015; Nauman, et al., 2010); the drive of a goal-oriented employee (Hofstede, 2015) and sharing similar goals (Nooteboom, 2004). 
A role not mentioned in the literature is that of the maverick trailblazer, here the Lake District officer, who first lobbied the Government and then circumvented many of the bureaucratic processes in order to get the job done. This individual probably paved the way for the more traditional approach taken by the New Forest and South Downs. Such impassioned individuals may need support to play their role in driving challenging change.

The clash of cultures between public and private sectors was evident, but was less clear-cut than described in the literature (Lewis \& Green, 1998; Russell \& Faulkner, 1999). National Parks were important because they could be both the innovators and risk-takers and provided a strategic overview, straddling the roles of both the private sector and the public sectors. However, there was an evident difference between the approach taken by the Lake District and the joint New Forest /South Downs bid, probably because of the different time scales for their bids. The Lake District adopted more of a risky, entrepreneurial approach, with the main aim of securing the grant, which resulted in having to sort out a number of issues once successful. The New Forest/South Downs team learnt from their experience and set up a strong and rigorous governance structure (see Kanter et al., 1992), more characteristic of the public sector as portrayed by Russell and Faulkner (1999) and UNWTO (2007).

Unlike companies introducing change into an existing organisation, these partnerships were formed to deliver change to a destination area, although many members, both individuals and organisations, had worked together before. Writing the bid served a number of the functions described in the processes. It created an implementation plan (see Kanter et al., 1992), formed the organisation (see Kanter et al., 1992) to implement the change, mobilised energy through identification of joint goals (Luecke, 2003) and gathered together a team or coalition (Kotter, 1996) with the purpose of improving visitor travel sustainability (Doppelt, 2003). It also generated the vision (see Kanter et al., 1992; Kotter, 1996; Luecke, 2003) helped by the potential of outside funding, although this had to be crafted for different audiences, for 
example enhancing the visitor experience for the tourism providers, promoting local growth for the LEP and the Department for Transport, reducing carbon emissions for many of the people involved and the Department for Transport, investing for future commercial operation for transport operators.

The timescales of the bid created a sense of urgency (see Kanter et al., 1992; Kotter, 1996), without it having to be generated internally. Some of the tight deadlines seem to have been effective in bringing about change, but some also worked against effective partnership operation. The instant announcement and award of the grant, certainly in the Lake District, meant that precious project time was lost as people were recruited and structures put in place, which could have been avoided with six months' preparation time between announcement and award. It is arguable whether the inability to carry funds over from year to year was effective in making change happen quickly or in fact was unrealistic given the context of working with local authorities and so many partners. In some cases, action before agreement, (Huxham \& Vangen, 2005) partly necessitated by the time scales of the funding, appears to have been an effective strategy.

The importance of communication (see Doppelt, 2003; Kanter et al., 1992; Kotter 1996) is stressed in many of the interviews. Engaging potential stakeholders often means spelling out the benefits they will derive from involvement (Purvis, et al., 2015). This emphasis, both on communication and on articulating the benefits for each stakeholder, emerged as crucial in the case studies. For example, tensions with residents arose because of the need to give one message to the Department for Transport in order to win the bid, but then not re-interpreting it to explain how, although targeted at visitor travel, the projects would also enhance travel for residents. These tensions were diffused by meeting and communicating with the resident groups. Careful messaging was also seen as important in maintaining the projects, with the need to speak the right language to engage the LEPs and the private sector, stressing economic development rather than sustainability as well as the visitor experience. 
However, in the cases described here there is some deviation from the stages of change outlined by Doppelt, 2003; Kanter et al., 1992; Kotter 1996 and Luecke, 2003. What the theories from business studies do not dwell upon is the external context for change. These projects were set up to improve the sustainability of visitor travel, but in a time when the political trend is away from public sector involvement in tourism and when economic criteria are dominating other evaluations such as sustainability, health, equity and justice. While many of the people working on the projects believed passionately in improving sustainability by reducing carbon emissions, they felt they needed to use other discourses to 'sell' the projects, particularly to those with the power to continue them. In addition, what is not apparent in these theories is the relative weighting and importance of the different factors of these theories. The relative importance of different factors came through very clearly in the case studies, particularly with regards to communication and communicating the benefits to stakeholders.

Last but not least, some of the elements of considered essential to reinforce change were missing in large part from these examples. Due to the short-term nature of the funding and the dissolution of the partnership which came together to the deliver the projects, there is limited opportunity to institutionalise the changes made (Kanter, 1992; Luecke, 2003) or to reward success (Doppelt, 2003). Monitoring, seen by Luecke (2003) as an element of reinforcing change was also not factored into the original bid.

To summarise, the experience of change documented in these two case studies is mapped against the original stages of change and presented in Table 3 below. The element of communication was considered so important it has been expanded separately (see Table 4). 
Table 3: Process of change in case study sites mapped against stages of change in literature

\begin{tabular}{|c|c|c|c|c|}
\hline $\begin{array}{l}\text { Kanter et al. } 10 \text { commandments } \\
\text { for executing change (1992) }\end{array}$ & $\begin{array}{l}\text { Kotter's eight-stage process for } \\
\text { successful organisational } \\
\text { transformation (1996) }\end{array}$ & Luecke's seven steps (2003) & $\begin{array}{l}\text { Doppelt's Leverage points } \\
\text { (2003) }\end{array}$ & $\begin{array}{l}\text { Experience of change in case } \\
\text { studies }\end{array}$ \\
\hline \multicolumn{5}{|l|}{ Implementing change } \\
\hline & & & & $\begin{array}{l}\text { Create initial enabling } \\
\text { conditions (i.e. lobbying for } \\
\text { inclusion of LSTF for SVTP and } \\
\text { National Parks) }\end{array}$ \\
\hline & & & $\begin{array}{l}\text { Change the dominant mind- } \\
\text { set and point out failures of } \\
\text { the old paradigm, describe } \\
\text { why new one is better }\end{array}$ & $\begin{array}{l}\text { Communication of benefits to } \\
\text { all stakeholders. Considered } \\
\text { to be one of the most crucial } \\
\text { elements }\end{array}$ \\
\hline $\begin{array}{l}\text { Analyse the organisation and its } \\
\text { need to change }\end{array}$ & & $\begin{array}{l}\text { Mobilise energy and } \\
\text { commitment through joint } \\
\text { identification of business } \\
\text { problems and their solutions }\end{array}$ & $\begin{array}{l}\text { Alter goals of the system and } \\
\text { establish the unambiguous } \\
\text { purpose of attaining } \\
\text { sustainability at a specific time } \\
\text { in the future }\end{array}$ & $\begin{array}{l}\text { Establishing partnership for } \\
\text { delivery, setting of priorities }\end{array}$ \\
\hline $\begin{array}{l}\text { Create a vision and common } \\
\text { direction }\end{array}$ & Developing a vision and strategy & $\begin{array}{l}\text { Develop a shared vision of how } \\
\text { to organise and manage for } \\
\text { competitiveness }\end{array}$ & & $\begin{array}{l}\text { Partnership contribution to } \\
\text { bid document and then } \\
\text { agreement of priorities }\end{array}$ \\
\hline Separate from the past & & & $\begin{array}{l}\text { Engage new people with } \\
\text { different perspectives and } \\
\text { skills }\end{array}$ & $\begin{array}{l}\text { People with passion brought } \\
\text { into the partnership }\end{array}$ \\
\hline Create a sense of urgency & Establish a sense of urgency & & & $\begin{array}{l}\text { Timescales of process created } \\
\text { sense of urgency }\end{array}$ \\
\hline Support a strong leader role & & Identify the leadership & & $\begin{array}{l}\text { Strong leadership and } \\
\text { empowerment of inspired } \\
\text { individuals }\end{array}$ \\
\hline Line up political support & Create a guiding coalition & & $\begin{array}{l}\text { Restructure the rules of } \\
\text { engagement, develop new } \\
\text { operational and governance } \\
\text { strategies }\end{array}$ & $\begin{array}{l}\text { Strong governance structure. } \\
\text { Political support ensured } \\
\text { through articulation of the } \\
\text { benefits. Considered to be } \\
\text { one of the most crucial } \\
\text { elements }\end{array}$ \\
\hline Craft an implementation plan & & & & Bid documentation \\
\hline
\end{tabular}




\begin{tabular}{|c|c|c|c|c|}
\hline $\begin{array}{l}\text { Kanter et al. } 10 \text { commandments } \\
\text { for executing change (1992) }\end{array}$ & $\begin{array}{l}\text { Kotter's eight-stage process for } \\
\text { successful organisational } \\
\text { transformation (1996) }\end{array}$ & Luecke's seven steps (2003) & $\begin{array}{l}\text { Doppelt's Leverage points } \\
\text { (2003) }\end{array}$ & $\begin{array}{l}\text { Experience of change in case } \\
\text { studies }\end{array}$ \\
\hline Develop enabling structure & Empowering broad-based action & & $\begin{array}{l}\text { Restructure the rules of } \\
\text { engagement, develop new } \\
\text { operational and governance } \\
\text { strategies }\end{array}$ & $\begin{array}{l}\text { Strong governance structure } \\
\text { (in New Forest / South } \\
\text { Downs). }\end{array}$ \\
\hline Communicate, involve people & Communicate the change vision & & $\begin{array}{l}\text { Communicate the need, } \\
\text { purpose, strategies and } \\
\text { benefits of sustainability } \\
\text { internally with employees and } \\
\text { externally among stakeholders }\end{array}$ & $\begin{array}{l}\text { Communication of benefits to } \\
\text { all stakeholders. Considered } \\
\text { to be one of the most crucial } \\
\text { stages. } \\
\text { Different stages of } \\
\text { communication required at } \\
\text { different stages of the process } \\
\text { See Table } 4 \text { for detail. }\end{array}$ \\
\hline \multicolumn{5}{|l|}{ Reinforcing change } \\
\hline $\begin{array}{l}\text { - Reinforce and institutionalise } \\
\text { change }\end{array}$ & $\begin{array}{l}\text { - Anchor new approaches in } \\
\text { culture } \\
\text { - Generate short-term wins } \\
\text { - Consolidate gains and } \\
\text { produce more change }\end{array}$ & $\begin{array}{l}\text { - Institutionalise success } \\
\text { through formal policies, } \\
\text { systems and structures } \\
\text { - Focus on results not activities } \\
\text { - Start change at the periphery } \\
\text { then let is spread } \\
\text { - Monitor and adjust strategies } \\
\text { in response to problems in } \\
\text { change process. }\end{array}$ & $\begin{array}{l}\text { - Foster and reward } \\
\text { innovation to continually } \\
\text { increase individual, team } \\
\text { and organisational } \\
\text { understanding, knowledge } \\
\text { and wisdom } \\
\text { - Adjust the parameters of } \\
\text { the system }\end{array}$ & $\begin{array}{l}\text { - Expectation that private } \\
\text { sector will continue with } \\
\text { much of the legacy. In } \\
\text { order for them to do this } \\
\text { they must see the benefits } \\
\text { and potential. } \\
\text { - Unfortunately, change } \\
\text { difficult to anchor in an } \\
\text { organisational sense due to } \\
\text { disintegration of team and } \\
\text { loss of expertise and } \\
\text { experience as a result of } \\
\text { short-term nature of the } \\
\text { funding. } \\
\text { - Results monitoring not part } \\
\text { of initial funding, but } \\
\text { subsequent monitoring } \\
\text { demonstrates success in } \\
\text { carbon reduction. }\end{array}$ \\
\hline
\end{tabular}

